\title{
Insulto y política en el discurso divergente: el caso de las FARC-EP*
}

\author{
YULIA KATHERINE CEDIEL GÓMEZ** \\ GIOHANNY OLAVE ARIAS ${ }^{* * *}$
}

Recepción: 28 de febrero de 2017

Aprobación: 6 de septiembre de 2017

Forma de citar este artículo: Cediel, Y. K. \& Olave, G. (2019). Insulto y política en el discurso divergente: el caso de las FARC-EP. Cuadernos de Lingüística Hispánica, (33), 85-106

(10) $10.19053 / 0121053 X . n 33.2019 .8951$

* Artículo producto de la investigación "Análisis del discurso político insurgente: la retórica vituperante de las Farc-Ep (20102012)", dirigida por Giohanny Olave en el pregrado de Letras en filología hispánica, de la Universidad de Antioquia.

** Filóloga Hispanista de la Universidad de Antioquia, Colombia. Grupo de investigación de Estudios del Lenguaje y la Educación. Correo electrónico:yuliakatherine@gmail.com. @https://orcid.org/0000-0003-0880-5172

*** Doctor en Lingüística de la Universidad de Buenos Aires. Grupo de investigación de Estudios del Lenguaje y la Educación. Profesor de tiempo completo en la Universidad Industrial de Santander, Colombia. Correo electrónico: olavearias@gmail.com Dhttps://orcid.org/0000-0001-6794-6472 


\section{Resumen}

En este artículo se analiza un corpus de comunicaciones de las Fuerzas Armadas Revolucionarias de Colombia, Ejército del Pueblo (FARC-EP), emitidas entre 2010 y 2012. El objetivo fue examinar la dimensión política del insulto en el discurso insurgente. A través de un método inductivo, desde la teoría fundamentada, el estudio describe el uso de enunciados que funcionan como insulto contra los adversarios construidos. Primero se identifican las condiciones sociohistóricas de emergencia de esa retórica vituperante; luego se determinan los contradestinatarios del vituperio y, finalmente, se muestra cómo estos usos se relacionan con la dimensión polémica construida en las comunicaciones públicas. Se concluye que el uso de insultos le permitió a las FARC-EP proyectar un ethos parresiasta, como preparación para su posterior inserción en el sistema democrático donde, cada vez más, se utilizan los insultos para conseguir adeptos.

Palabras clave: epideixis política, conflicto armado colombiano, retórica argumentativa, vituperio.

\section{Insult and Politics in Divergent Discourse: Case Study of the FARC-EP}

\section{Abstract}

This is a research about a corpus composed by communications of the guerrilla Fuerzas Armadas Revolucionarias de Colombia- Ejército del Pueblo (FARC-EP), which was published between 2010 and 2012. The objective is to analyze the political dimension of the vituperation in the insurgent discourse. Through an inductive method, from grounded theory, the research describes the uses of utterances as an insult against the opponents, which are created by the insurgent discourse. Foremost, the research identifies the social and historical emergence conditions of the vituperative rhetoric. Then the research determinates the destination of the insults and, finally, shows how those uses are related with the polemic dimension of the public communications. The conclusion of the research is that the insult uses allowed the FARC-EP to create a parresiastic ethos, as a preparation for the insertion in the democratic system, where is becoming more common the use of the insults to get voters.

Keywords: argumentative rhetoric, Colombian armed conflict, political epideixis, vituperation. 


\section{Insulte et politique dans le discours divergent : le cas des FARC-EP}

\section{Résumé}

Dans cet article, on analyse un corpus de communications des Forces Armés Révolutionnaires de la Colombie, Armée du Peuple (FARC-EP), publiées entre 2010 et 2012. L'objectif a été celui d'examiner la dimension politique de l'insulte dans le discours insurgent. À travers une méthode inductive, dès la théorie fondée, l'étude décrit l'utilisation d'énoncés qui fonctionnent comme une insulte contre les adversaires constitués. D'abord, on identifie les conditions sociohistoriques d'émergence de cette rhétorique injurieuse. Ensuite, on détermine les contra-destinataires de l'injure. Finalement, on montre comment ces utilisations son liées à la dimension polémique construite dans les communications publiques. On conclut que l'utilisation des insultes a permis aux FARC-EP de projeter un ethos parrèsiaste, en tant que préparation pour une insertion future dans le système démocratique où, de plus en plus, on utilise des insultes pour obtenir des adhérents.

Mots clés : épideixis politiques, conflit armé colombien, rhétorique argumentative, injure.

\section{Insulto e política no discurso divergente: o caso das FARC-EP}

\section{Resumo}

Este artigo analisa um corpus de comunicações das Forças Armadas Revolucionárias da Colômbia, Exército do Povo (FARC-EP), publicado entre 2010 e 2012. 0 objetivo foi examinar a dimensão política do insulto no discurso insurgente. Através de um método indutivo, baseado na teoria fundamentada, o estudo descreve o uso de enunciados que funcionam como um insulto contra os adversários construídos. Primeiro, são identificadas as condições sócio históricas de emergência dessa retórica vituperaria; então, os contradestinários do vituperativo são determinados e, finalmente, é mostrado como esses usos estão relacionados à dimensão controversa construída nas comunicações públicas. Conclui-se que o uso de insultos permitiu às FARC-EP projetar um ethos paroquial, em preparação para sua posterior inserção no sistema democrático, onde os insultos são cada vez mais utilizados para ganhar adeptos.

Palavras-chave: epideixia política, conflito armado colombiano, retórica argumentativa, vituperação. 


\section{Introducción}

En la actualidad se están implementando los compromisos establecidos en el Acuerdo Final para la Terminación del Conflicto y la Construcción de una Paz Estable y Duradera, firmado entre el Gobierno colombiano y las FARC-EP en el 2016, como documento final del proceso de paz que se desarrolló en La Habana, Cuba, durante cuatro años. El periodo que antecede a estos diálogos estuvo marcado por el endurecimiento de las posiciones insurgentes y contrainsurgentes, en el marco de la Política Integral de Seguridad y Defensa para la Prosperidad (Ministerio de Defensa, 2011), adelantada por el presidente Juan Manuel Santos. Así, los discursos ${ }^{1}$ gubernamentales y guerrilleros que circularon durante 2010-2012 corresponden a la última etapa de la política que buscaba solucionar el conflicto interno exclusivamente por la vía armada.

Este artículo se centra en los discursos guerrilleros de ese periodo. Su objetivo es sintetizar cómo funcionó políticamente el insulto contra los enemigos construidos en sus comunicaciones, a partir de una parte de los resultados de una investigación reciente (Cediel, 2016); con ese fin, en el artículo se abordará la función polémica de los insultos en los discursos de esa guerrilla. El análisis de estas regularidades en sus modos de decir permite ver cómo se gestionan diferencias a propósito de cuestiones sociales ante las cuales se manifiestan desacuerdos, desde posiciones políticas en divergencia. Esta investigación contribuye al entendimiento del discurso de las FARC-EP como parte de la oposición política en el país y a la comprensión de esta guerrilla como actor histórico insurgente. Esta comprensión resulta fundamental en un periodo donde se avizora la transformación de las FARC-EP en un actor político legal y la aparición de desacuerdos en el espacio democrático, por su inserción en dicho sistema.

\section{Fundamentación teórica}

Desde los estudios de la cortesía y, particularmente, a partir de los aportes de la pragmática sociocultural (Bravo \& Bernal, 2015; Brenes, 2011; Fuentes, 2016; Fuentes \& Alcaide, 2008; y, en general, Estudios sobre el Discurso de la Cortesía en Español [EDI$\mathrm{CE}$ ], 2017), se ha analizado el insulto como un acto descortés que transgrede las normas sociales de los intercambios comunicativos. Esa transgresión responde a premisas culturales que hacen específica la evaluación descortés en cada comunidad de práctica (Kaul, 2014). Desde este enfoque se ha privilegiado el problema de la imagen social construida a

1 A pesar de que existen numerosas definiciones de discurso, en este texto se entiende como la "huella de un acto de comunicación sociohistóricamente determinado" (Charaudeau \& Maingueneau, 2005, p.180); además, se hace énfasis en la idea de que "el discurso contribuye a definir su contexto y puede modificarlo durante la enunciación" (2005, p.182). 
través de actos (des)corteses, esto es, cómo autoafirman su identidad los sujetos y cómo se integran a los grupos donde actúan. Para enfatizar en este tipo de función social identitaria, al respecto del insulto en el habla juvenil amistosa, Zimmermann (2005) propuso el término anticortesía. Esta categoría ha servido para adelantar análisis sobre el uso de disfemismos en el lenguaje juvenil, orientado hacia la construcción de imágenes positivas en los endogrupos (Escamilla, Vega, Morales, Samper \& Torres 2014; Gómez, 2014; Hernández, 2014).

En los ámbitos anglófono e hispanófono de los estudios del discurso político, el insulto no ha sido un objeto de especial interés ${ }^{2}$. Por el contrario, en los análisis recientes (Arnoux \& Zaccari, 2015; Gallardo-Paúls, 2014; Fairclough \& Fairclough, 2012; Laborda, 2012; Ochieng, Oketch \& Hameed, 2016; Olave \& Arnoux, 2016; Van Dijk, 2008; Wodak, 2012; entre otros) la violencia verbal es leída como síntoma de actitudes antipolíticas y de cierto vaciamiento o desviación del lenguaje políticamente correcto.

Las caracterizaciones discursivas de la guerrilla FARC-EP (Bolívar, 2006; Estrada, 2004; Sabucedo, Barreto, Borja, De la Corte \& Durán, 2006) han seguido esa misma tendencia. Estas visiones han coincidido en que el uso del insulto en el discurso guerrillero lo deslegitimó como actor político, toda vez que la enunciación vituperante contradice el intercambio argumentativo razonado, esto es, le resta racionalidad a las interacciones políticas, cuya función sería la resolución de diferencias a través de argumentos e, inclusive, amenaza la dinámica de los sistemas democráticos (Álvarez, 2009; Bolívar, 2008; González, 2010; Núñez, 2000). Lo anterior se debe a que desde algunas visiones normativas de la argumentación, como la pragmadialéctica (Van Eemeren \& Grootendorst, 2004; Van Eemeren, 2010), argumentar es una actividad verbal y social donde se presentan desacuerdos que deben resolverse por vías puramente racionales.

No obstante, en este reporte de investigación el vituperio es abordado desde otros aspectos que permiten entender la dimensión persuasiva de su uso. El uso del vituperio en política se ha empezado a estudiar recientemente desde enfoques retórico-argumentativos no normativos, que permiten una comprensión tanto del elemento lingüístico en sí mismo como de su función dentro de las polémicas públicas (Danblon, 2002; Hastings, 2009; Orkibi, 2012; Olave, 2013, 2016; Rosier, 2012). Hablar de retórica argumentativa significa deshacer la dicotomía normativa entre estas disciplinas (del lado proscrito, la retórica como manipulación y, del otro, la argumentación como racionalidad del buen

2 En Colombia, el estudio de Lozano (2011) permite ver que las investigaciones retóricas no son predominantes en el país, donde existe una tradición más bien dialectológica. Este hecho resalta la importancia de realizar análisis sobre estos temas para aportar a la comprensión de la oposición política en Colombia, especialmente, a los estudios sobre el discurso insurgente. 
juicio) y reconocerlas como partes de un continuum cuya base común es la persuasión. En este enfoque, el trabajo de Amossy $(2000,2008)$ ha resultado fundamental para entender que no solo existe argumentación en el discurso intencionalmente persuasivo, sino también en la dimensión argumentativa que tiene toda palabra en la esfera pública, por su capacidad de influir sobre los otros. Como lo resumen Danblon y Nicolas (2010, pp. 33-34), las perspectivas retórico-argumentativas están interesadas en comprender la efectividad persuasiva de ciertos usos de la palabra pública, no para condenar las motivaciones que llevarían a razonamientos falaciosos, sino precisamente para explicar y comprender la eficacia de esos mecanismos.

El género epidíctico, del cual forma parte el vituperio, versa sobre juicios de valor negativos que se difunden en el espacio público, para buscar la adhesión del auditorio, lo cual se logra reforzando los valores comúnmente admitidos y los rechazados (Perelman \& Olbrechts-Tyteca, 1989), o bien, modificándolos (Cassin, 2008), para lograr la unión de la polis en torno a esos valores. Este género es el único en el que el objeto de juicio no se confunde con el objeto de discurso: en él no solo se habla sobre el asunto, sino que se resalta la manera en que se emite el discurso (Danblon, 2002, p.129). Otras características del género epidíctico es que el orador presenta su discurso como si fuera verdad, lo cual genera en el auditorio la sensación de que lo enunciado refiere valores universales que deben ser aceptados. Esta estrategia del orador provoca un efecto de validez que es aprehendido por los espectadores. Así, la indignación, producto de la ofensa, es más fuerte que el elogio en el momento de influir en la emoción colectiva (Danblon, 2002, p.130). Esto se da porque la indignación es una emoción política que presupone normas y reglas. El uso del modo expresivo le permite al orador mantener la realidad social, compuesta por convenciones a las que los ciudadanos se adhieren y que se han establecido por medio del discurso.

Para Amossy (2008), asimismo, el objetivo de un discurso epidíctico es reafirmar la identidad del grupo y fortalecerlo en torno a valores morales, para lo cual se suele apelar al sentimiento. La construcción del ethos (Amossy, 2010) tiene aquí un papel fundamental, dado que la imagen de sí que formula el orador sobre sí mismo, contribuye a la construcción de identidades y de diferencias en el discurso. De ahí que los enunciados vituperantes sean una muestra de cómo el enunciador configura verbalmente relaciones de diverso tenor con él mismo, para reafirmarse o construir colectivos solidarios; con los otros, para polemizar con los enemigos; y con los discursos anteriores a los que apela, para actualizar tópicos ideológicos. Las polémicas introducidas se entienden aquí como modos retórico-argumentativos caracterizados por la descalificación de los oponentes, la dicotomización de las posiciones y la polarización del espacio social (Amossy, 2014). Ade- 
más, se trata de polémicas movilizadas o sostenidas por el uso de memorias discursivas, es decir, de la articulación, selección y adaptación de discursos políticos anteriores dentro de un mismo sistema de creencias (Courtine, 1981).

La construcción de esas relaciones implica la construcción discursiva de los sujetos (Arrieta, 2013, Olave, 2018) y, en este caso específico, la representación de amigos y enemigos políticos a través del vituperio. Verón (1987) propone, de hecho, que la construcción de "prodestinatarios" y "contradestinatarios" es consustancial al discurso político, pues desde esta múltiple destinación se excluye o se adhiere a los colectivos a través de los enunciados. Atenderemos, entonces, a la dimensión política del insulto en cuanto funciona en la discursividad guerrillera como eje de la identificación y la definición de sus contradestinatarios.

En adelante explicaremos los aspectos metodológicos y expondremos los resultados del estudio, relacionando los enunciados vituperantes con sus condiciones históricas de producción y describiendo los contradestinatarios construidos. En esa descripción revisaremos el contenido polémico de los vituperios en función de las memorias discursivas que actualizan. Orientaremos las conclusiones hacia una dirección convergente de los enunciados vituperantes: la construcción de un cierto ethos que apela al efecto de parrhesía (Foucault, 2004) para mostrarse como el sujeto que se pone en riesgo vital al "atreverse" a decir la verdad de manera violenta. Un tal ethos parrhesiasta constituyó una demostración de fuerza frente al enemigo y una estrategia de preparación militante de las tropas, antes de sentarse a dialogar con el Gobierno, en 2012. Pensamos estos resultados, además, en torno a la dimensión estratégica de ese tipo de ethos en el escenario de la política contemporánea, donde el insulto aparece de manera cada vez más recurrente como una impostura crítica contra la llamada "política tradicional".

\section{Metodología}

La fuente primaria de este artículo la constituye un corpus compuesto por 93 comunicaciones públicas de las FARC-EP, emitidas entre 2010 y 2012 (FARC-EP, 20102012). Ese corpus, usado en otras investigaciones de mayor alcance (Cediel, 2016; Olave, 2016), incluye una variedad de géneros textuales, como artículos de opinión, cartas, comunicados y homenajes. De esas 93 comunicaciones se extrajeron los enunciados en los que aparecieron formas de usos vituperantes. Estos enunciados fueron relacionados, en primera instancia, con las temáticas o tópicos que referían, con lo cual los vituperios hallados quedaron asociados con seis acontecimientos principales de la vida política nacional. Cada uno de estos sucesos clave reúne la dispersión de los discursos analizados y agrupa un conjunto de enunciados vituperantes que serán ejemplificados en la sección 
de resultados. Estos acontecimientos se utilizarán como eje vertebrador para presentar los fenómenos analizados.

El análisis siguió un método inductivo, a partir de los procedimientos establecidos por la teoría fundamentada (Gibbs, 2012). Con apoyo del software Atlas ti 6.2 se codificaron (Strauss \& Corbin, 2002, p.124) las regularidades halladas, según las condiciones sociohistóricas que les dieron origen y las funciones de los vituperios en el orden de lo polémico.

La identificación de las condiciones sociohistóricas de emergencia de la retórica vituperante permite situar la aparición de este tipo de enunciados en los comunicados del grupo insurgente y ordenar la presentación de los resultados. Las diversas formas de uso del vituperio no pretenden conformar una tipología, dadas las limitaciones metodológicas que impone el recorte de los datos y el escaso interés que tiene el perfil taxonómico para el enfoque retórico-argumentativo, antes especificado. Se trata, en cambio, de relacionar esos usos con las dimensiones política y argumentativa del género epidíctico, dentro de las cuales se inscriben, para comprender su efectividad persuasiva. En el artículo se privilegia la descripción del criterio polémico, desde dos aspectos del vituperio: el primero es el interdiscurso, que tiene en cuenta la relación que establece cada enunciado vituperante con referentes ideológicos anteriores. El segundo es el tipo de contradestinatario, en el cual se explicita el adversario contra el cual va dirigido cada vituperio particular.

\section{Resultados}

Los enunciados vituperantes en el discurso guerrillero aparecen articulados con un conjunto de situaciones históricas en la vida política del país y de las dinámicas propias del conflicto interno. Entre estos acontecimientos resaltan seis que motivaron una mayor cantidad de enunciados vituperantes: el asesinato del jefe militar de las FARC-EP, alias 'Mono Jojoy'; las elecciones presidenciales de 2010; el Plan Nacional de Desarrollo (PND) del primer Gobierno de Juan Manuel Santos; la crisis fiscal; la ola invernal (fenómeno de La Niña); y la Ley de Víctimas y Restitución de Tierras. En la Tabla 1 se ejemplifica y analiza la relación entre los insultos, sus condiciones sociopolíticas de emergencia y la función polémica que cumplen. Se subraya de nuevo que los ejemplos provistos en la Tabla no constituyen la totalidad del corpus analizado, sino que ilustran la función polémica atribuida y cada uno representa un subconjunto de los enunciados vituperantes asociados con los acontecimientos que los motivaron. En el desarrollo posterior de la Tabla 1 también se introducen otras ejemplificaciones. 
Tabla 1. Producción y función polémica de insultos en el discurso de las FARC-EP (2010-2012)

\begin{tabular}{|c|c|c|}
\hline $\begin{array}{c}\text { Hecho } \\
\text { sociopolítico }\end{array}$ & Ejemplo $^{3}$ & Función polémica \\
\hline $\begin{array}{ll}\text { Asesinato } & \text { del } \\
\text { Mono Jojoy } & \end{array}$ & $\begin{array}{l}\text { "Santos el matón. Muy estúpido el anuncio de San- } \\
\text { tos en el sentido de que matará a Alfonso Cano de } \\
\text { la misma manera como mató al comandante Jorge } \\
\text { Briceño" (7 de marzo de 2011), (FARC-EP, 2010- } \\
\text { 2012) }\end{array}$ & $\begin{array}{l}\text { Desacreditar la política de segu- } \\
\text { ridad pública y las operaciones } \\
\text { contra los cabecillas guerrille- } \\
\text { ros, ridiculizando los discursos } \\
\text { del presidente Santos. }\end{array}$ \\
\hline $\begin{array}{l}\text { Elecciones presi- } \\
\text { denciales }\end{array}$ & $\begin{array}{l}\text { "[...] no podemos tragarnos la historieta de que la } \\
\text { elección de Juan Manuel Santos es la ratificación de } \\
\text { la democracia en Colombia, porque sencillamen- } \\
\text { te es la convalidación tramposa del régimen de } \\
\text { terror oligárquico [...] Estos son algunos de los } \\
\text { factores que componen el triunfo de la "democra- } \\
\text { cia" que el imperio yanqui y la oligarquía lacaya } \\
\text { de Colombia pretenden legitimar con sus rancias } \\
\text { elecciones" (15 de agosto de 2010), (FARC-EP, } \\
2010-2012) \text {. }\end{array}$ & $\begin{array}{l}\text { Deslegitimar la elección del } \\
\text { presidente Santos, poniendo en } \\
\text { duda la transparencia y sobe- } \\
\text { ranía del sistema democrático } \\
\text { colombiano. }\end{array}$ \\
\hline $\begin{array}{l}\text { Plan Nacional de } \\
\text { Desarrollo }\end{array}$ & $\begin{array}{l}\text { "¿Se puede llamar buen gobierno o democrática } \\
\text { una institucionalidad que trasfiere el bien público } \\
\text { a las corporaciones privadas siguiendo las recetas } \\
\text { neoliberales o bajo el influjo de la ambición que } \\
\text { ya ha hecho bastantes escándalos de corrupción? } \\
\text { Están podridas hasta los tuétanos, sus extensiones } \\
\text { conducen a las mafias del narcotráfico y el para- } \\
\text { militarismo, su innegable maquinaria de terror } \\
\text { con la que ejercen gran parte del dominio social, } \\
\text { político y económico" ( } 4 \text { de sep., 2011), (FARC-EP, } \\
\text { 2010-2012). }\end{array}$ & $\begin{array}{l}\text { Denunciar el plan nacional de } \\
\text { desarrollo como una política co- } \\
\text { rrupta y criminal, favorecedora } \\
\text { de las élites. }\end{array}$ \\
\hline Crisis fiscal & $\begin{array}{l}\text { "Una plétora de promesas y un conjunto de per- } \\
\text { sonalidades -incluidos los especímenes que se } \\
\text { autoproclaman de "izquierda"-, han secundado la } \\
\text { asquerosa propaganda del presidente de los "fal- } \\
\text { sos positivos" tendiente a crear una falsa matriz de } \\
\text { opinión según la cual, los seculares problemas de } \\
\text { la nación serán solucionados a la vuelta de la esqui- } \\
\text { na. Pero más allá de los ardides propagandísticos, } \\
\text { su demagogia presenta múltiples contradicciones } \\
\text { desde el punto de vista de la realidad económica } \\
\text { del país" (7 de abril, 2011), (FARC-EP, 2010-2012). }\end{array}$ & $\begin{array}{l}\text { Generar desconfianza sobre las } \\
\text { políticas económicas del presi- } \\
\text { dente Santos y sospechar de la } \\
\text { veracidad en su manejo mediá- } \\
\text { tico. }\end{array}$ \\
\hline
\end{tabular}

3 En todos los ejemplos de este documento, las cursivas han sido añadidas por los autores para resaltar las formas textuales de la vituperación. 


\begin{tabular}{|c|c|c|}
\hline $\begin{array}{c}\text { Hecho } \\
\text { sociopolítico }\end{array}$ & Ejemplo $^{3}$ & Función polémica \\
\hline Ola invernal & $\begin{array}{l}\text { "...] las muestras de altruismo de los mas se ve } \\
\text { arruinada por la larvada labor de una pandilla } \\
\text { de trubanes pertenecientes en su mayoría a la clase } \\
\text { política gobernante. En complicidad con empleados } \\
\text { de Colombia Humanitaria, gobernadores y alcaldes; } \\
\text { los bandidos se robaron miles de millones de pesos } \\
\text { de los fondos destinados a los afectados [...] Aho- } \\
\text { ra Santos, remedando la hija del faraón de Egipto } \\
\text { pretende rescatar de las aguas al pueblo colom- } \\
\text { biano tal como lo hizo aquella dama con Moisés al } \\
\text { sustraerlo de las aguas del Nilo. Su papel en este } \\
\text { caso se parece más al del gallinazo del diluvio que } \\
\text { abandonó el arca de Noé. Su cinismo e hipocresía } \\
\text { carecen de límites" (22 de mayo, 2012), (FARC-EP, } \\
\text { 2010-2012). }\end{array}$ & $\begin{array}{l}\text { Descalificar las gestiones guber- } \\
\text { namentales frente a la emer- } \\
\text { gencia invernal, denunciando } \\
\text { prácticas corruptas de la clase } \\
\text { dirigente y desenmascarando e } \\
\text { oportunismo político del presi- } \\
\text { dente Santos. }\end{array}$ \\
\hline $\begin{array}{l}\text { Ley de Víctimas } \\
\text { y Restitución de } \\
\text { Tierras }\end{array}$ & $\begin{array}{l}\text { "Pretende engañar Juan Manuel a quienes promete } \\
\text { tierra sin comprometerse a cambiar la estructura } \\
\text { latifundista del campo. En una basura como el } \\
\text { proyecto de Ley } 085 \text { de restitución de tierras no } \\
\text { tenemos sino un folleto de apariencias pensado } \\
\text { para, al final de cuentas, crear las condiciones que } \\
\text { permitan un macro-despojo legal de la tierra" (21 } \\
\text { de febrero, 2011), (FARC-EP, 2010-2012). }\end{array}$ & $\begin{array}{l}\text { Acusar de engaño a la política } \\
\text { agraria del presidente Santos, } \\
\text { por reproducir el modelo de } \\
\text { concentración en la tenencia de } \\
\text { la tierra. }\end{array}$ \\
\hline
\end{tabular}

El discurso guerrillero intervino en los hechos sociopolíticos del periodo analizado como un discurso indignado de denuncia y desconfianza contra la gestión gubernamental. La principal herramienta retórica de esa discursividad fue la vituperación; el lugar de enunciación y sus condiciones de ilegalidad y clandestinidad explican esta extensión de la violencia física hacia la palabra como un modo de "hacerse oír" en el espacio público.

Un elemento común a esos usos vituperantes fue la presencia de contradestinatarios con los cuales no se pretendía dialogar ni establecer algún debate. Por el contrario, el contradestinatario fue construido por la insurgencia como punto de anclaje para dirigirse a un tercero de doble instancia: la tropa guerrillera y la ciudadanía desarmada, a quienes sí se pretendía persuadir. De esta manera, las FARC-EP utilizaron los vituperios con el ánimo de reforzar y ganar adeptos contra las clases dirigentes y sus esferas de influencia, como el sector privado y los medios de comunicación.

Se puede afirmar que en las comunicaciones públicas estudiadas existen algunas regularidades en el aspecto polémico. Sus interdiscursos más frecuentes son el antiestadounidense y el socialista, relacionados directamente por la tradición antiimperialista del socialismo. El antiestadounidismo fue construido a través de califi- 
caciones insultantes, como proyanqui, gansteril, macartismo contumaz, receta gringa e imperialismo yanqui, entre otras construcciones asociadas con su línea ideológica, como se ejemplifica en la segunda cita, extraída de los documentos programáticos de esta guerrilla: "[...] es necesario forjar en el proceso del enfrentamiento armado una fuerza militar revolucionaria capaz de derrotar y vencer la estrategia total de la guerra total surgida del contubernio de la oligarquía colombiana con el imperialismo yanqui" (FARC-EP, 1978, p. 25).

Tanto las declaraciones presentes en sus estatutos, como en las comunicaciones del periodo previo al proceso de paz, actualizan la tradición insultante del discurso antiimperialista, proveniente de la bibliografía panfletaria socialista (Angenot, 1982). La memoria socialista es reconocible en el uso de vituperios, como enemigos de clase, oligarquía, ultraconservador y cátedra neoliberal, en los cuales el insulto no se encuentra marcado en el nivel semántico literal, sino en los ecos políticos y las formaciones ideológicas a las cuales remiten esas lexías y sintagmas. Para el denominado "marxismo-leninismo", la posición ideológica declarada en los estatutos de la organización (FARC-EP, 1978), construcciones adjetivas como ultraconservador, burgués, oligarca, etc. se constituyen en ofensas, aun cuando ese calificativo carecería de función vituperante desde otra orilla ideológica.

A partir de la adscripción a los principios fundamentales del marxismo-leninismo (FARC-EP, 1978, pp.7-8), se ha reconocido que la concepción socialista de las FARCEP es heterodoxa (Ferro \& Uribe, 2002, p.123), o bien, superficial (Pécaut, 2015). En estas concepciones se ha puesto en cuestión durante medio siglo la legitimidad del grupo armado como actor político y, sobre todo, como contradictor del poder hegemónico. En el extenso debate sobre este asunto en la bibliografía histórica, sociológica y politológica de la guerrilla fariana - por ejemplo, Beltrán (2015), Centro Nacional de Memoria Histórica -CNMH- (2014), Medina (2009), Pizarro (2015), entre otros-, se ha afirmado que la llamada "combinación de todas las formas de lucha" ayudó a restar valor a los reclamos históricos de la guerrilla y a reforzar la postura gubernamental, según la cual la insurgencia había desplazado la política por las armas. Se puede afirmar, además, que el estilo conflictivo y contestatario de la palabra guerrillera ha abonado la percepción de su incapacidad para configurarse como opositor político legítimo, pese a que sus reivindicaciones, inicialmente agrarias, se extendieron a otras problemáticas de país y lograron cooptar diversos sectores populares que contribuyeron al crecimiento de esta guerrilla.

En el aspecto retórico, Olave $(2016,2017)$ ha propuesto profundizar en las formas en que el discurso insurgente actualizó y representó el discurso socialista europeo y 
latinoamericano en función de sus propios intereses y de sus condiciones de ilegalidad, clandestinidad y desgaste político del propio discurso socialista en la época contemporánea. Añadimos aquí a esa discusión que durante el último tramo de la Política de Seguridad Democrática (2010-2012), la activación de la memoria socialista se realizó a través de interdiscursividades mediadas por la vituperación: "No hay duda, estamos frente a un gobierno de clara estirpe reaccionaria, representado por un alto exponente de la más rancia oligarquía colombiana, garante seguro desde hace más de dos siglos, de los intereses del imperio en el continente" (30 de abril de 2011), (FARC-EP, 2010-2012).

La crítica al sistema político establecido usualmente se apuntala en las formas vituperantes y, con ello, activa sentimientos de desprecio contra las élites dominantes. Apelar a la historia, en estos casos, significa profundizar la indignación amplificando la gravedad de las acusaciones por su sistematicidad histórica. Los tópicos socialistas de la dominación de clase y la dicotomía oligarcas/pueblo aparecen anclados y radicalizados a través de la fuerza de los vituperios: "[...] la extrema derecha y los sectores más putrefactos e impúdicos de la oligarquía pro-yanqui (sic), trastocada por el narcotráfico y su mentalidad siniestra se afianzaron en el poder" (13 de agosto, 2010), (FARC-EP, 20102012).

Después del asesinato de su jefe militar, en septiembre de 2010, las comunicaciones de las FARC-EP estuvieron enfocadas en remarcar su posicionamiento ideológico a partir del homenaje al combatiente caído como figura del héroe revolucionario sacrificado — y redimido — por la causa: "[...] la caída del gran guerrillero revivió en el presidente Santos el desvarío del fin del fin de la guerrilla [...] Hemos luchado y continuaremos haciéndolo, con valor, entrega y sacrificio por derrocar este régimen podrido de las oligarquías" (8 de oct., 2010), (FARC-EP, 2010-2012).

Generalmente, los contradestinatarios del discurso guerrillero fueron aquellos que representaban roles de autoridad, en especial el expresidente Álvaro Uribe Vélez y el presidente Juan Manuel Santos. También aparecieron con frecuencia las instituciones estatales, entre las cuales resaltaron el Congreso y el Ejército Nacional.

Un contradestinatario particular de estas comunicaciones fueron los medios de comunicación. Este contradestinatario "no es el interlocutor propiamente dicho, sino que se encuentra más bien rebajado al rango de objeto: se habla de él, pero no se le dirige la palabra" (Garand, 2016, p.124); por ejemplo, en el siguiente enunciado las FARC-EP no pretenden establecer un diálogo con personajes particulares aludidos, sino englobarlos en la categoría despreciativa gran prensa, para descalificarlos ante el auditorio: 
Viendo la ignominia de algunos reporteruchos y gacetilleros de la gran prensa encarnizados frente al cadáver del líder guerrillero, aullando sus denuestos, es deber moral deplorar la bajeza ética de quienes pretenden inducir la opinión nacional a favor del guerrerismo y del terrorismo de Estado. (8 de oct. de 2010), (FARC-EP, 2010-2012)

El valor negativo adjudicado a la nominalización gran prensa radica en la ironía de esa grandeza en contraste con su bajeza ética y con la animalización (encarnizados frente al cadáver... aullando) construida para presentar al contradestinatario. Las FARC-EP pretendieron descalificar la información dada por los medios de comunicación, acusándolos de estar al servicio de los intereses gubernamentales. Con vituperios como "reporteruchos", pusieron en duda la calidad de la información dada y, por tanto, deslegitimaron el cubrimiento noticioso hecho por los "gacetilleros". Así, pusieron en entredicho las afirmaciones realizadas y reclamaron un espacio público para posicionar su propia versión de los hechos.

En torno a las elecciones presidenciales del año 2010, se encontró que las FARCEP dieron cuenta en sus comunicaciones de una preparación para el proceso de paz y, por esto, mitigaron la defensa socialista de la toma del poder por las armas, focalizando expresiones a favor de una solución negociada del conflicto: "[...] nosotros creemos que vale la pena intentar romper ese círculo maldito y apostarle más bien a la reconciliación y a la paz" (3 de marzo, 2012), (FARC-EP, 2010-2012).

El círculo maldito, que hacía referencia a la guerra, desplazaba las responsabilidades sobre la violencia y objetivaba el conflicto, al no presentar los agentes del mismo: la guerra no parecía tener un responsable. De esta manera, la guerrilla pretendía llegar a los diálogos de paz con una responsabilidad mínima sobre la violencia en el país, lo cual les permitiría ganar terreno en la negociación. Si bien la paz siempre fue tematizada en las comunicaciones públicas de las FARC-EP, en la serie de discursos analizados estuvo mediada por el insulto hacia la guerra o, por extensión, contra el grupo de los guerreristas, del cual ellos se esforzaron por desmarcarse.

Asimismo, la contradestinación construida para el sistema electoral colombiano buscó restarle validez al triunfo electoral de las diversas organizaciones políticas legales. Sin embargo, los discursos guerrilleros declararon claramente su intención democrática, es decir, hubo una doble intención en los insultos hacia el sistema vigente. Por un lado, criticaron las elecciones y las organizaciones participantes: "Esta es la realidad de la formulación más estrepitosamente escandalosa de la 'democracia electoral' que le dio 
y le sigue dando triunfos a la mafia fascista que gobierna Colombia con el respaldo de Washington" (12 de agosto, 2010), (FARC-EP, 2010-2012).

Y, por otro lado, hicieron una defensa de la democracia que les permitiría postularse como un actor protagónico dentro de este sistema:

la estrategia y práctica paramilitar que ya se le conocía y su fascistoide rechazo visceral a una solución política del conflicto, todo ese vergonzoso velo, está a punto de caer, lo que abrirá nuevas perspectivas a la civilidad y a la democracia verdadera (Cano, 2011, junio 11)

Particularmente en las comunicaciones que emergieron en torno a la Ley de Víctimas y Restitución de Tierras, se identificó que el contradestinatario más frecuente fue el rol de autoridad representado por el presidente Juan Manuel Santos. A través del insulto, la guerrilla buscó diferenciarse de su contradestinatario directo: "En conclusión, el actual Presidente no ha dejado de ser el mismo granuja que era cuando fungía como feroz ministro de los 'falsos positivos'; es decir, de las incontables ejecuciones” (21 de feb., 2011), (FARC-EP, 2010-2012).

En este enunciado, las FARC-EP buscaron descalificar al presidente Santos y negar que promoviera una ley a favor de las víctimas, a partir del recuento de sus acciones políticas pasadas, con las que lo acusaban de victimario. De esta forma, la guerrilla se separaba de quien sería su interlocutor político en los diálogos de La Habana. Esta separación pretendía evitar posibles sospechas sobre una convergencia entre la guerrilla y el Gobierno Santos en torno a las políticas públicas, en general, y alrededor de la política de víctimas, en particular. De esta manera, se fortalecía la posición fariana como una oposición al Gobierno que capitalizaba los reclamos de las víctimas del conflicto y las reclamaba como parte de su lucha armada.

Si bien el contradestinatario que predominó en los enunciados vituperantes fue el rol de autoridad, representado por el presidente Juan Manuel Santos, esto no puede verse como una muestra de la imposibilidad de un diálogo con el gobierno de turno, sino que debe analizarse como una movida estratégica en función del proceso de paz posterior. La vituperación funcionó como una estrategia para diferenciarse del adversario en un momento en el que se avizoraba un acercamiento al Gobierno, es decir, se establecían claramente las diferencias para que el diálogo posterior no fuera visto como una entrega, sino como una negociación entre dos partes igual de legítimas. En ese sentido, se construyó una oposición política desde el extremismo y la radicalización de las posturas en medio del conflicto armado, lo cual era evidente en los discursos en los que predominaba 
la enunciación vituperante. De este modo, incluso la contradestinación directa 0 interpelación explícita al enemigo - poco frecuente en los discursos analizados-, orientaba las provocaciones hacia el desenmascaramiento de un adversario presentado como aquel que ocultaba la verdad y frente al cual la guerrilla se arrogaba el deber de rebelarla para la ciudadanía: "Retomar la Agenda [de paz] que quedó pendiendo (sic) en El Caguán. El gobierno del que usted hizo parte, se negó a abordarla diez años atrás, condenándonos a todos a esta Troya sangrienta (...) Sin mentiras, santos, sin mentiras" (28 de feb., 2012), (FARC-EP, 2010-2012).

Toda vez que el contradestinatario del vituperio no es llamado a un diálogo, sino que es vilipendiado para que el auditorio lo considere como un 'otro' despreciable, en el insulto político el papel del tercero "tiene el rol principal: es a él a quien se dirige el discurso, es a él al que se corteja, en ocasiones a espaldas del adversario" (Garand, 2016, p.128). En el acercamiento a la ciudadanía, como auditorio por seducir, resultó clave la construcción de la guerrilla como un actor irreverente frente al orden establecido, en declarada rebeldía contra las injusticias sociales de las que acusaba al "régimen", y fuertemente armada, tanto física como verbalmente. La guerrilla se mostraba, así, como una insurgencia que en vez de aparecer vencida, llegaba fortalecida a las negociaciones de paz.

\section{Conclusiones}

El propósito de este artículo fue analizar la función polémica del insulto en el discurso de la guerrilla FARC-EP, desmovilizada en la actualidad. Las conclusiones que siguen están fundamentadas en el análisis de 93 comunicaciones públicas de ese grupo insurgente, emitidas en el periodo 2010-2012. Su dimensión polémica fue estudiada y ejemplificada específicamente en este texto, mientras que otros aspectos que resultan complementarios y coherentes con este análisis pueden consultarse en el texto producto de la investigación terminada recientemente (Cediel, 2016).

La retórica vituperante emerge en condiciones de confrontación polémica, donde predominan la desacreditación del otro y su desconocimiento como contradictor legítimo (Amossy, 2014). Este combate verbal, sin embargo, no carece de dimensión política; como vimos, los actores insultan para tomar distancia ideológica, axiológica y emocional de sus enemigos, radicalizar posicionamientos en la lucha y seducir a los auditorios. En la guerra, entonces, ese distanciamiento queda inscrito no solo en la movilidad de los cuerpos, sino también en la de los discursos. 
Una diferenciación así, responde al dominio de la lógica de la guerra y a la perspectiva de su finalización; en el periodo previo a los diálogos de paz que se llevarían a cabo en La Habana entre el 2012 y el 2016, la vituperación fue la principal herramienta de diferenciación usada por la guerrilla. Ella buscaba consolidarse como fuerza opuesta y contradictor político marginado; los auditorios tendrían que diferenciarlos claramente con respecto a sus enemigos, una vez los vieran sentados dialogando en una misma mesa.

De acuerdo con lo anterior, los vituperios cumplían una doble función política: la primera fue la radicalización de las posturas frente al enemigo, lo cual servía para que, con miras a un proceso de paz, el auditorio tuviera claras las diferencias entre los planteamientos de cada una de las partes. La segunda función fue la construcción de identidad colectiva, una forma de generar adhesión dentro del grupo afín al locutor. Esta función puede estar relacionada con el propósito de la guerrilla de participar en espacios democráticos, es decir, que la guerrilla buscó conseguir y mantener partidarios para sus propuestas al margen del estilo de la política tradicional que denunciaban a través de la vituperación.

Es posible leer, entonces, esa demostración de fuerza más allá de la violencia verbal irracional. Por el contrario, se trata de una violencia cuya racionalidad apunta a la construcción de un cierto ethos relacionado con la indignación y el coraje del oprimido y con la vocería de las víctimas del régimen gubernamental. Así, el contenido de los vituperios se orientó hacia la puesta en evidencia de la canalla del enemigo, esto es, hacia una especie de "revelación de la verdad" en la esfera pública, desde la posición del vulnerado y poniéndose a sí mismo en riesgo por esas "verdades" enunciadas con vehemencia.

El eco de la lectura foucaultinana de la parrēsía ( $\pi \alpha \rho \rho \eta \sigma \alpha)$ griega aquí es evidente. Para Foucault (2004), el parresiasta emerge cuando el hecho de decir la verdad puede dar lugar a consecuencias costosas para quien la dijo. La verdad del parresiasta se convierte, así, en el corazón del desafío y en el drama de la libertad; la verdad constituye un peligro y el parresiasta es consciente del riesgo que asume al decirla. Cada época tiene diferentes fronteras para lo indecible y los parresiastas son quienes las traspasan; si asumimos que el vituperio transgrede esos regímenes de decibilidad, es posible relacionarlo con la parrēsía.

Aclaramos, sin embargo, que Foucault (2004) propone la parrēsía en el mundo griego como una categoría ontológica; sin embargo, aquí la entendemos como una construcción discursiva y específicamente retórica en la dimensión del ethos, debido a que este tratamiento de la verdad es ante todo una estrategia en la construcción de la iden- 
tidad verbal, que es utilizada para fomentar la adhesión del auditorio a las creencias del locutor. Al hablar de construcción del parresiasta hacemos énfasis en que toda realidad es definida y modificada durante la enunciación (Charaudeau \& Maingueneau, 2005, p. 182), y es en ese sentido en el que la parrēsía puede entenderse más como una construcción discursiva que como una característica ontológica. Las FARC-EP se muestran a sí mismas como portadoras de la verdad y así buscan legitimidad para acusar y despreciar a otros actores que, según ellos, deben ser desenmascarados porque ocultan o manipulan la información frente al pueblo colombiano.

Los discursos de las FARC-EP pretendieron, desde un ethos colectivo, denunciar crímenes gubernamentales y mostrarse así como voceros de una población desarmada que no podía enfrentarse al poder representado por las instituciones. En esta misma línea, la guerrilla quiso reflejar la imagen de la víctima que se refugia en las armas para poder decir lo que nadie más puede decir, para poder ser portadora de una verdad que debe respaldarse con la fuerza. Se puede afirmar, en síntesis, que este actor se construyó a sí mismo como un parresiasta armado.

Por último, el análisis de los usos del insulto de las FARC-EP constituye un aporte al estudio de la retórica insurgente en Colombia. Este es un campo de investigación que puede ser abordado interdisciplinarmente, para comprender el discurso de este grupo contestatario que, ahora, pasa a ser parte de la democracia en el país.

Pero, más allá del caso tratado, el estudio del uso de los vituperios en la esfera política es un campo amplio y urgente para las ciencias del lenguaje, especialmente en un momento donde se viene reconociendo el uso de la violencia verbal como un factor decisivo en las contiendas electorales ${ }^{4}$. La retórica vituperante deviene en estrategia de diferenciación y en impostura contra lo "políticamente correcto", desde donde se había proscrito el insulto en el debate y en la comunicación de los grupos y figuras que pretenden representar a los colectivos. En lugar del rechazo a estos fenómenos desde reclamos éticos, conviene preguntarse cómo es que el estilo vituperante ha ingresado a la política

4 Con miras a las elecciones presidenciales de Colombia en 2018, una de las candidatas que se ha posicionado ha sido Claudia López quien, según el periodismo colombiano, se ha ganado la imagen de "una mujer con rabia frente al estado actual de las cosas y, en consecuencia, una furibunda crítica prácticamente de todo. Su permanente presencia en los medios no obedece a que estos compartan sus ideas, sino simplemente a que su 'botafuegos' siempre tiene rating" [...]. El caso de Donald Trump también ha sido comentado en este sentido: "Por estos días lo que da votos es patear el tablero. El estado de ánimo del electorado no es tanto el de elegir al mejor, sino a alguien diferente [...]. El insulto desproporcionado hasta hace poco descalificaba, pero después del triunfo de Trump, quien llegó a la Casa Blanca a punta de insultar a diestra y siniestra, las reglas de juego han cambiado" (Semana, 2017). 
para representar a los descontentos y ha logrado elegir democráticamente a sus representantes gubernamentales en el continente, incluso a nivel presidencial.

\section{Referencias}

Álvarez, A. (2009). Anticortesía y política. Lengua y Habla, 13, 19-33.

Amossy, R. (2000). L'argumentation dans le discours. París: Nathan.

Amossy, R. (2008). Argumentation et analyse du discours: perspectives théoriques et découpages disciplinaires. Argumentation et Analyse du discours, 1. Recuperado de http://aad. revues.org/200

Amossy, R. (2010). La présentation de soi. Ethos et identité verbal. París: PUF.

Amossy, R. (2014). Apologie de la polémique. París: PUF.

Angenot, M. (1982). La parole pamphlétaire. Typologie des discours modernes. París: Payot.

Arnoux, E. \& Zaccari, V. (coords.) (2015). Discurso y política en Sudamérica. Buenos Aires: Biblos.

Arrieta, L. M. (2013). La construcción de los sujetos en el discurso del expresidente Uribe Vélez: un análisis desde las tonalidades valorativas y los actos de habla. Cuadernos de Lingüística Hispánica, 21, 103-116.

Beltrán, M.A. (2015) Las FARC-EP (1950-2015): Luchas de ira y esperanza. Bogotá: Desde Abajo.

Bolívar, A. (2008). "Cachorro del imperio" versus "Cachorro de Fidel": los insultos en la política latinoamericana. Discurso \& Sociedad, 2(1), 1-38.

Bolívar, Í. (2006). Discursos emocionales y experiencias de la política. Las FARC y las AUC en los procesos de negociación del conflicto (1998-2005). Bogotá: Uniandes.

Bravo, D. \& Bernal, M. (coords.) (2015). Perspectivas sociopragmáticas y socioculturales del análisis del discurso. Buenos Aires: Dunken.

Brenes, M. (2011). Descortesía verbal y tertulia televisiva: análisis pragmalingüístico. Berna: Peter Lang.

Cano, A. (2011, junio 11). Siempre será posible construir escenarios de negociación con el Gobierno. Entrevista realizada por Publico.es. Extraída desde: http:/www.publico.es/ internacional/siempre-sera-posible-construir-escenarios.html

Cassin, B. (2008 [1995]). El efecto sofístico. Buenos Aires: Fondo de Cultura Económica. 
Cediel, Y. (2016). Análisis del discurso político insurgente: la retórica vituperante de las FARCEP (2010-2012). (Trabajo monográfico inédito). Universidad de Antioquia, Medellín.

Charaudeau, P. \& Maingueneau, D. (2005). Diccionario de análisis del discurso. Buenos AiresMadrid: Amorrortu.

Centro Nacional de Memoria Histórica -CNMH- (2014). Guerrilla y población civil (3. $\left.{ }^{\mathrm{a}} \mathrm{ed}.\right)$. Bogotá: Autor.

Courtine, J.J. (1981). Quelques problèmes théoriques et méthodologiques en analyse du discours, à propos du discours communiste adressé aux chrétiens. Langages, 62(15), 9-128.

Danblon, E. (2002). Rhétorique et Racionalité. Bruxelles: Editions de L'Universite de Bruxelles.

Danblon, E. \& Nicolas, J. (Dir.) (2010). Les rhétoriques de la conspiration. Paris: CNRS.

Estudios sobre el Discurso de la Cortesía en Español - EDICE- (2017). Presentación. Recuperado de: http://edice.org/acerca-del-programa/

Escamilla, J., Vega, G., Morales, E., Samper, J. \& Torres, L. (2014). Humos, imágenes discursivas y (anti)cortesía en conversaciones estudiantiles universitarias. Signo y Seña, 26, 49-68. Recuperado de: http://revistas.filo.uba.ar/index.php/sys/issue/viewIssue/8/9

Estrada, F. (2004). Las metáforas de una guerra perpetua. Estudios sobre pragmática del discurso en el conflicto armado colombiano. Medellín: EAFIT.

Fairclough, I. \& Fairclough, N. (2012). Political Discourse Analysis. A Method for Advanced Students. London and New York: Routledge.

FARC-EP (2010-2012). Corpus FARC 2010-2012. Recuperado de: https:/www.dropbox.com/ $\mathrm{sh} / \mathrm{nsswja33s17drmr/AAA70T49BdIVYUS7VNfeSowPa?n=13002999 \& oref=e}$

FARC-EP (1978). Estatutos de las Farc-Ep. Extraído desde: http:/farc-ep.co/wp-content/ uploads/2013/10/Estatutos.pdf

Ferro, J. \& Uribe, G. (2002). El orden de la guerra: las FARC-EP entre la organización y la política. Bogotá: CEJA, Universidad Javeriana.

Foucault, M. (2004[1983]). Discurso y verdad en la antigua Grecia. Curso en la Universidad de Berkeley. Buenos Aires: Paidós.

Fuentes, C. (2016). (Des)cortesía, imagen social e identidad como categorías sociopragmáticas en el discurso público. En D. Dumitrescu \& D. Bravo (coords.), Roles situacionales, interculturalidad y multiculturalidad en encuentros en español (pp.165-192). Buenos Aires: Dunken. 
Fuentes, C. \& Alcaide, E. (2008). (Des)Cortesía, agresividad y violencia verbal en la sociedad actual. Sevilla: Servicio de Publicaciones de la Universidad de Sevilla.

Gallardo-Paúls, B. (2014). Usos políticos del lenguaje. Un discurso paradójico. Barcelona: Anthropos.

Garand, D. (2016). La función del ethos en la formación del discurso conflictivo. En S. Montero (comp.), El análisis del discurso polémico. Disputas, querellas y controversias (pp. 123-137). Buenos Aires: Prometeo.

Gibbs, G. (2012). El análisis de datos cualitativos en investigación cualitativa. Madrid: Morata.

Gómez, D. (2014). Los disfemismos: lenguaje juvenil de anticortesía. (Tesis de maestría). Universidad de Antioquia, Medellín.

González, M. (2010). Las funciones del insulto en debates políticos televisados. Discurso $\varepsilon$ Sociedad, 4(4), 828-852.

Hastings, M. (2009). De la vitupération. Le pamphlet et les régimes du "dire vrai" en politique, Mots. Les langages du Politique, 91. D0I: 10.4000/mots.19188

Hernández, G. (2014). Manifestación de la cortesía y la anticortesía en jóvenes de la provincia de Buenos Aires, Argentina: usos y representaciones de las "malas palabras" e insultos. Signo y Seña, 26, 23-47. Recuperado de http://revistas.filo.uba.ar/index.php/sys/ issue/viewIssue/8/9

Kaul, S. (2014). Delimitación de unidades extralingüísticas de análisis del discurso de (des)cortesía. Signo y Seña, 26, 7-22. Recuperado de http://revistas.filo.uba.ar/ index.php/sys/issue/viewIssue/8/9

Laborda Gil, X. (2012). Lágrimas de cocodrilo. Análisis del discurso político. Madrid: UOC.

Lozano, M. (2012). Breves notas sobre la investigación lingüística en Colombia. Cuadernos de Lingüística Hispánica, 19, 13-22

Medina, C. (2009). FARC-EP y ELN. Una historia política comparada (1958-2006). Notas para una bistoria politica. (Tesis de doctorado). Universidad Nacional de Colombia, Bogotá.

Ministerio de Defensa (2011). Política Integral de Seguridad y Defensa para la Prosperidad. Recuperado de http://www.ceedcds.org.ar/Srd-LibBL/COL/POL_INT_SEG_DEF.pdf

Núñez, E. (2000). Aproximación al léxico del lenguaje político español. (Tesis doctoral). Universidad de Málaga, España.

Ochieng, D., Oketch, 0. \& Hameed, A. (2016). Political Discourse in Emergent, Fragil, and Failed Democracies. USA: Information Science Reference. 
Olave, G. (2013). La argumentación epidíctica en el discurso político del conflicto armado colombiano contemporáneo. En M.A. Vitale \& P.J. Salazar (eds.), Rhetoric in South America (pp. 45-57) República de Sudáfrica: África Rethoric Publishing.

Olave, G. (2016). El Bolívar de las FARC. Usos de la memoria bolivariana en el discurso guerrillero. En G. Olave \& E. N. de Arnoux (coords.), Discurso y política en Colombia: problemáticas actuales (pp. 159-196). Medellín: La Carreta.

Olave, G. (2017). Construcciones retóricas de la oposición política en el conflicto armado colombiano. Los discursos de la guerrilla FARC-EP y del presidente Juan Manuel Santos. 2010-2012. (Tesis inédita de doctorado en Lingüística). Universidad de Buenos Aires, Argentina.

Olave, G. (2018). Ethos y temporalidad. El discurso de Juan Manuel Santos al recibir el Premio Nobel de la Paz. Cuadernos de Lingüística Hispánica, 31, 81-102.

Olave, G. \& Arnoux, E. (coords.) (2016). Discurso y política en Colombia. Medellín: La Carreta.

Orkibi, E. (2012). L'insulte comme argument et outil de cadrage dans le mouvement "antiSarko". Argumentation et Analyse du Discours, 8. DOI: 10.4000/aad.1335

Pécaut, D. (2015). Una lucha armada al servicio del statu quo social y político. En Contribución al entendimiento del conflicto armado en Colombia (Comisión Histórica del Conflicto y sus Víctimas), 599-651. Bogotá: Desde Abajo.

Perelman, C. \& Olbrechts-Tyteca, L. (1989). Tratado de la argumentación. La nueva retórica. Madrid: Gredos.

Pizarro, E. (2015). Una lectura múltiple y pluralista de la historia. En Contribución al entendimiento del conflicto armado en Colombia (Comisión Histórica del Conflicto y sus Víctimas), 5-98. Bogotá: Desde Abajo.

Rosier, L. (2012). Introduction. Argumentation et Analyse du Discours, 8, 1-8.

Sabucedo, J., Barreto, I., Borja, H., De la Corte, L. \& Durán, M. (2006). Legitimación de la violencia y contexto: análisis textual del discurso de las FARC-EP. Estudios de Psicología, 27(3), 279-291.

Semana (2017, 7 de ene.). El 'botafuegos' de Claudia López hará ruido en campaña. Revista Semana. Recuperado de http://www.semana.com/nacion/articulo/claudia-lopez-anunciosu-candidatura-a-la-presidencia-de-la-republica/511537

Strauss, A. \& Corbin, J. (2002). Bases de la investigación cualitativa. Medellín: Universidad de Antioquia. 
Van Dijk, T. (2008). Discourse and Power. New York: Palgrave Macmillan.

Van Eemeren, F. (2010). Strategic Maneuvering in Argumentative Discourse. Extending the Pragma-Dialectical Theory of Argumentation. Amsterdam, Philadelphia: John Benjamins.

Van Eemeren, F. \& Grootendorst, R. (2004). A Systematic Theory of Argumentation: The Pragma-Dialectical Approach. Cambridge: Cambridge University Press.Verón, E. (1987). La palabra adversativa. En E. Verón, L. Arfuch, M. Chirico, E. De Ipola, N. Goldman, M. I. González et al., El discurso político. Lenguajes y acontecimientos (pp. 13-26). Buenos Aires: Hachette.

Wodak, R. (2012). Politics as Usual: Investigating Political Discourse in Action. In P. Gee \& M. Handford (eds.), The Routledge Handbook of Discourse Analysis (pp. 525-540). London and New York: Routledge Handbooks.

Zimmermann, K. (2005). Construcción de la identidad y anticortesía verbal. Estudio de conversaciones entre jóvenes masculinos. En D. Bravo (ed.), Estudios de la (des)cortesía en español (pp. 245-270). Buenos Aires: Dunken. 